\title{
First Seizure While Driving (FSWD) - An Underestimated Phenomenon?
}

\author{
Bernd Pohlmann-Eden, Nina Hynick, Karen Legg
}

\begin{abstract}
Background: Seizures while driving are a well known occurrence in established epilepsy and have significant impact on driving privileges. There is no data available on patients who experience their first (diagnosed) seizure while driving (FSWD). Method: Out of 311 patients presenting to the Halifax First Seizure Clinic between 2008 and 2011, 158 patients met the criteria of a first seizure (FS) or drug-naïve, newly diagnosed epilepsy (NDE). A retrospective chart review was conducted. FSWD was evaluated for 1) prevalence, 2) clinical presentation, 3) coping strategies, and 4) length of time driving before seizure occurrence. Results: The prevalence of FSWD was 8.2\%. All 13 patients experienced impaired consciousness. Eleven patients had generalized tonic-clonic seizures, one starting with a déjà-vu evolving to visual aura and a complex partial seizure; three directly from visual auras. Two patients had complex partial seizures, one starting with an autonomic seizure. In response to their seizure, patients reported they were i) able to actively stop the car $(n=4$, three had visual auras), ii) not able to stop the car resulting in accident ( $\mathrm{n}=7)$, or iii) passenger was able to pull the car over $(n=2)$. One accident was fatal to the other party. Twelve out of 13 patients had been driving for less than one hour. Discussion: FSWD is frequent and possibly underrecognized. FSWD often lead to accidents, which occur less if preceded by simple partial seizures. Pathophysiological mechanisms remain uncertain; it is still speculative if complex visuo-motor tasks required while driving play a role in this scenario.
\end{abstract}

RÉSUMÉ: Une première crise convulsive en conduisant un véhicule automobile, un phénomène sous-estimé? Contexte : Les crises convulsives survenant lors de la conduite d'un véhicule automobile sont un phénomène bien établi dans l'épilepsie et ont un impact significatif sur le permis de conduire. Il n'y a pas de données sur les patients qui ont leur première crise convulsive (diagnostiquée) en conduisant (PCCC). Méthode : Parmi les 311 patients examinés à la clinique de consultation pour une première crise convulsive à Halifax entre 2008 et 2011, 158 patients rencontraient les critères d'une première crise convulsive ou d'une épilepsie nouvellement diagnostiquée alors que le patient était sans traitement. Nous avons effectué une revue rétrospective de ces dossiers. Nous avons évalué la prévalence de la PCCC, sa présentation clinique, les stratégies d'adaptation et depuis combien de temps le patient conduisait avant que la crise convulsive ne survienne. Résultats : La prévalence de la PCCC était de $8,2 \%$. Treize patients ont présenté une altération de l'état de conscience. Onze patients ont présenté une crise tonico-clonique généralisée, une crise ayant débuté par un déjà-vu évoluant en aura visuel et une crise partielle complexe, et chez 3 patients elle a été précédée directement d'auras visuels. Deux patients ont eu des crises partielles complexes dont l'une a débuté par une crise d'épilepsie autonome. En réponse à leur crise, les patients ont rapporté soit qu'ils avaient été capables d'arrêter l'automobile ( $\mathrm{n}=4$, trois avec aura visuel), qu'ils n'ont pas été capables d'arrêter l'automobile ce qui a provoqué un accident ( $\mathrm{n}=7)$, ou que le passager a été capable d'arrêter l'automobile en bordure de la route $(\mathrm{n}=2)$. Un accident a causé la mort d'occupants dans le véhicule qui a été heurté. Douze des 13 patients conduisaient depuis moins d'une heure au moment de la crise. Discussion : Une PCCC est un phénomène fréquent et potentiellement sous-diagnostiqué. Une PCCC est souvent la cause d'accidents, moins fréquemment si elle est précédée par une crise d'épilepsie partielle simple. Ses mécanismes physiopathologiques demeurent obscurs et et nous ne savons pas si les tâches visuo-motrices complexes exigées pour la conduite automobile y contribuent.

Can J Neurol Sci. 2013; 40: 540-545

Frequent medical conditions such as cardiovascular disease (CVD), Diabetes mellitus (DM), and epilepsy can all affect driving capability. There are extensive and detailed restrictions on driving for patients with DM as well as CVD, which can be found in the Canadian Council of Motor Transport Administrators (CCMTA) medical standards for drivers, as well as the Canadian Medical Association (CMA) Drivers Guide., ${ }^{1,2}$ Research into the risks associated with these conditions and motor vehicle accidents, however, has been inconclusive. It is suggested that $0.1 \%$ of collisions are related to $\mathrm{CVD},{ }^{3}$ while the prevalence of collisions associated to DM is unknown, and research about an added risk in those on insulin therapy has been contradictory and inconclusive. ${ }^{4,5}$

The coincidence of driving and a seizure leading to an accident was first reported more than 100 years ago in $1906 .^{6}$ This observation resulted in a general prohibition against driving with epilepsy. In 1930, in the United Kingdom, epilepsy became the first medical condition to result in an absolute ban from driving. This occurred after a man experiencing a seizure drove his car into a crowd of spectators watching the Changing of the Guard at Buckingham Palace, killing an onlooker. ${ }^{7}$ Since then numerous researchers and clinicians from all over the world started to look at the relationship between car accidents and seizures from many different perspectives. No more than 1 in

From the Division of Neurology, Halifax Infirmary, Dalhousie University, Halifax, Nova Scotia, Canada.

Received September 27, 2012. Final Revisions Submitted January 3, 2013. Correspondence to: Bernd Pohlmann-Eden, Division of Neurology, Room No 3838 Halifax Infirmary, Dalhousie University, 1796 Summer St, Halifax, Nova Scotia, B3H 3A7, Canada. Email: B.Pohlmann-Eden@dal.ca. 
1000 total accidents in Sweden was found to be possibly related to seizures. ${ }^{8}$ In an early German study almost one third of 500 patients with epilepsy were involved in car accidents; in $20 \%$ of those the accident was most likely the result of a seizure. ${ }^{9}$ These initial observations prompted different nations to develop guidelines for people with epilepsy, with regard to driving privileges, in wide variety of ways. ${ }^{10}$ These guidelines, initially very restrictive, have become more and more liberal over time. Currently, most countries prohibit patients who have experienced a single unprovoked seizure from driving (group 1 license) for a minimum period of six months, (in circumstances such as a clearly acutely provoked seizure most often three months) mainly because many studies have shown that the risk for seizure recurrence (SR) is highest with in the first six months following a first seizure, ${ }^{11}$ and is considered at this point to be lower than $20 \% .^{12}$ A very recent study took the data from a large randomised controlled trial of immediate versus deferred treatment for newly presenting seizures to assess the risk for SR; for patients who started antiepileptic treatment the risk for SR was significantly below the required $20 \%$ (14\% including the confidence interval) within six months; the untreated group also had an overall SR risk below 20\% (18\%), however the upper limit of the confidence interval was greater than $20 \%$, showing $23 \%$, identifying a small subgroup of patients with remote symptomatic seizures and pathological electroencephalography (EEG) to be at slightly increased risk for SR. ${ }^{12}$

Prohibiting someone from driving in a mobile society is often a personal disaster, limits autonomy and contributes to a multifactorial disadvantage in the labour market. ${ }^{13}$ Physicians must consider both the individual patient's situation as well as the overall welfare of the public when making a medical recommendation as to medical suitability to drive. Current recommendations by the CCMTA suggest that all individuals who have experienced a single unprovoked seizure undergo a detailed neurological assessment and EEG testing before becoming eligible for any class of license. ${ }^{1}$ They further recommend that driving privileges be suspended for six months if epileptiform activity is seen on EEG; unless the neurologist recommends otherwise. The CMA also provides guidelines to assist physicians in determining if their patient is medically fit to safely drive a motor vehicle. ${ }^{2}$ In the setting of a single unprovoked seizure it is their recommendation that the patient should not drive for a minimum of three months and not before having a complete neurological examination including awake and sleep recorded EEG and appropriate neuroimaging, preferably magnetic resonance imaging (MRI).

There is a paucity of evidenced-based data on the significance of the association between interictal epileptiform abnormalities on routine EEG and the ability to predict future seizures. A recent study using prolonged (six-hour) video-EEG, rather than routine EEG monitoring, to predict fitness to drive in patients with previously diagnosed epilepsy, suggested that routine EEG showed some statistical significance but that positive prolonged six-hour video-EEG was more useful in ability to reasonably predict the likelihood of seizure relapse, as well as early seizure relapse, and the researchers recommend that it would be a useful method of investigation in the evaluation of a patient's fitness to drive. ${ }^{14}$
Little has been reported on how persons with epilepsy respond to a seizure event while driving. Epilepsy patients, on antiepileptic drugs, presenting with preceding "warning" auras were reported to have a reduced risk for car accidents. ${ }^{15}$

In addition to this pragmatic and highly relevant aspect of seizure occurrence (and related coping strategies) and driving privileges, it is also of major theoretical interest how the individual seizure threshold is impacted and defined by neurobiological factors of the epilepsy syndrome and the interference with complex activities such as driving. There is almost no research on drug-naive patients experiencing their first seizure while driving (FSWD). This makes these cases especially interesting. Resting states and brain activity during sleep were thought to be more conducive to a lowered seizure threshold, particularly for symptomatic seizures, than the activity level present when doing something as complex as driving. A study in 212 adults, albeit with known refractory focal epilepsy, failed to provide support for the hypothesis that cognitive exertion has an adverse effect on seizure control. ${ }^{16}$ Recent research in established epilepsy has found that the protective factor of mental stimulation is cancelled out by a prolonged duration of an activity with multifactorial sensory input. ${ }^{17}$ Further studies in chronic epilepsy suggest that thinking activity and action programming ${ }^{18}$ as well as intensive neuropsychological testing ${ }^{19}$ can be provocative for both seizure and epileptiform discharge occurrence. Comparable data on drug-naïve first seizure patients are entirely lacking.

\section{METHODS}

In spring 2008, a First Seizure Clinic (FSC) was established in Halifax, Nova Scotia as part of a modern comprehensive, academically orientated epilepsy program. Three hundred and eleven patients were referred to the Halifax FSC between July of 2008 and August 2011. These individuals were referred from various general practitioners, inpatient services and emergency departments for investigations as to whether an epileptic seizure or a newly diagnosed epilepsy were the reason for a first ever presentation with loss of consciousness. All patients were clinically assessed by an epileptologist (BPE) in collaboration with a specialty nurse practitioner (KL) including extensive history taking, collateral history, family history, social history, and physical examination. As part of the comprehensive assessment, every patient was asked about the detailed circumstances under which their seizure occurred. It was specifically recorded in our database if the patient experienced FSWD. For confirmation of clinical diagnosis, all patients received routine EEG, sleep-deprived EEG or both. All patients had an emergency cranial computerized tomography (CT) prior to their presentation to the FSC. To further detect possible subtle epileptogenic structural lesions, all patients (except patient 9) underwent a MRI of the brain following an epilepsy protocol (coronal slices, FLAIR sequences). Clinical, functional (EEG) and morphological data (CT, MRI) were documented in a prospective database. The diagnosis of a first epileptic seizure (FS) or newly diagnosed epilepsy (NDE) was made or confirmed by the epilepsy specialist (BPE) based on several pieces of critical information including typical clinical presentation, eyewitness accounts when available, postictal signs such as tongue bite, urine loss, significant confusion, exhaustion, and muscle 
soreness, EEG and CT/MRI results. Newly diagnosed epilepsy was diagnosed if there was evidence for more than one seizure separated at least by 24 hours. All patients were scheduled for follow-ups after 6,12 and 14 months.

A retrospective chart review of all 311 patients was conducted in order to identify the number of patients with confirmed diagnosis of a FS or with specific focus on those who had their $\mathrm{FS}$, or in the cases of NDE their presenting seizure, while driving. Seventeen patients were excluded as they had either a previous history of epilepsy or evidence of prior treatment with antiepileptic drugs (AED). Out of the remaining 294 patients, 52 patients were considered to be not eligible as a result of being lost to follow-up and subsequently did not have a complete assessment (two out of those had a FSWD). Further 84 patients were excluded as a result of a non-seizure diagnosis including syncope, psychogenic non-epileptic seizure, transitory ischemic event, migraine, positional vertigo or other unclassifiable nonepileptic events (two out of those had an event while driving). 158 patients were found to have a strict FS or NDE (Figure) and were analyzed for the question of having a FSWD. This group was subsequently carefully analyzed with regard to 1) seizure type, 2) time driving before seizure, 3) ability to control the car, 4) injuries, 5) provoking factors, 6) EEG- results, 7) CT/MRI results, and 8) outcome. Ethics approval was obtained from the Capital Health Research Ethics Board, Halifax. Nova Scotia, Canada.

\section{RESULTS}

Thirteen out of our $158(8.2 \%)$ patients presenting with either a FS or NDE were identified (Figure) to have experienced their most likely first ever epileptic seizure while driving (FSWD). The Table gives a detailed overview of all results of each subject. A witness was present to provide a collateral history for all seizures while driving, except for cases twelve and thirteen.

The proportion of individuals with other or uncertain diagnoses, or those lost to follow up who had experienced an event while driving were $3.6 \%$ and $3.8 \%$ respectively.

\section{Age and sex}

Age ranged from 20 to 67 years (average 38.0 years, median 32 years). Ten FSWD patients were male (76.9\%).

\section{Seizure type}

The majority, 11 patients, experienced generalized tonicclonic seizures (GTCS). One evolved from a simple partial seizure (déjà-vu) to a complex partial seizure prior to secondarily generalizing. A further 4 out of the 11 patients with GTCS gave evidence for a preceding subtle event suspicious for simple partial seizures (SPS), four reported visual auras, of which one had a brief preceding déjà-vu sensation. One patient reported vasovagal symptoms such as "blackening, feeling sickness and close to fainting" before evolving to a clearly documented sGTCS. We did not count these symptoms as simple partial seizure. One patient with a complex-partial seizure observed a preceding piloerection as possible part of an autonomic seizure. One further patient experienced a complex partial seizure with no secondary generalization.

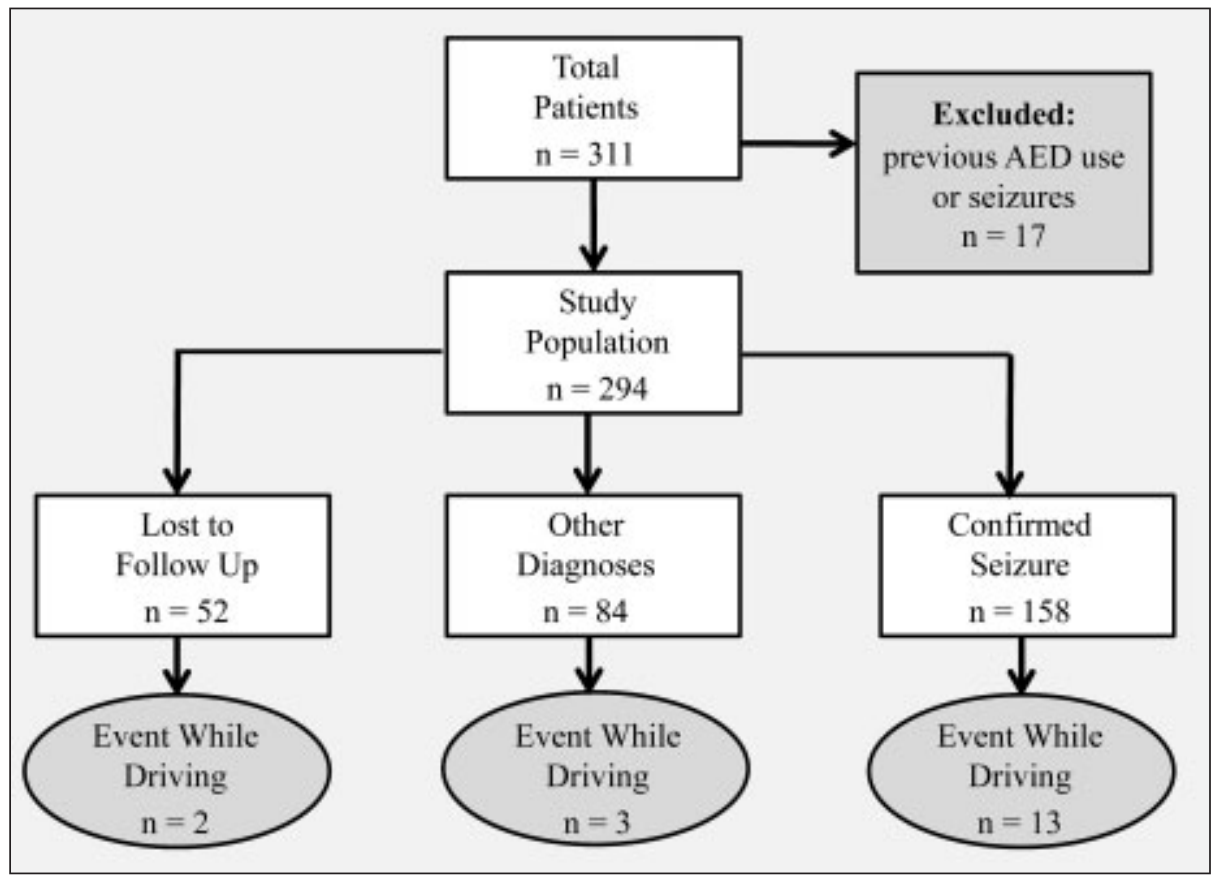

Figure: Overview of patients presenting to the Halifax First Seizure Clinic and Study Population. 
Table: Clinical, functional (EEG), morphological (CT, MRI) data, coping strategies, and short-term outcome on 13 patients with first seizure while driving

\begin{tabular}{|c|c|c|c|c|c|c|c|c|c|c|}
\hline Case & $\begin{array}{l}\text { Age: } \\
\text { Sex }\end{array}$ & $\begin{array}{l}\text { Main } \\
\text { Seizure } \\
\text { type }\end{array}$ & $\begin{array}{l}\text { Preceding } \\
\quad \text { SPS }\end{array}$ & $\begin{array}{l}\text { Time } \\
\text { driving } \\
\text { before } \\
\text { seizure }\end{array}$ & $\begin{array}{l}\text { Ability } \\
\text { to } \\
\text { control } \\
\text { vehicle }\end{array}$ & Injuries & $\begin{array}{l}\text { Provoking } \\
\text { factors }\end{array}$ & $\begin{array}{l}\text { EEG } \\
\mathrm{R}=\text { routine } \\
\mathrm{sID}=\text { sleep } \\
\text { deprived }\end{array}$ & $\begin{array}{l}\text { MRI } \\
\text { CT }\end{array}$ & $\begin{array}{c}\text { AED } \\
\text { Outcome }\end{array}$ \\
\hline 1 & 53:M & CPS & None & $1-5 \mathrm{~min}$ & 3 & None & $\begin{array}{c}\text { chronic } \\
\text { sleep deprivation }\end{array}$ & $\begin{array}{l}\text { Normal } \\
(R / s \mid D)\end{array}$ & $\begin{array}{l}\text { cerebellar } \\
\text { atrophy }\end{array}$ & $\begin{array}{c}\text { No AED } \\
\text { behavioural modification } \\
\text { only. }\end{array}$ \\
\hline 2 & $26: M$ & $\begin{array}{c}\text { CPS } \\
\text { sGTCS }\end{array}$ & $\begin{array}{c}\text { Deja-vue } \\
\text { visual aura }\end{array}$ & $60 \mathrm{~min}$ & 2 & $\begin{array}{l}\text { Fatal to } \\
\text { other party }\end{array}$ & None & $\begin{array}{l}\text { Normal } \\
(\mathrm{R} / \mathrm{s} \mid \mathrm{D})\end{array}$ & $\begin{array}{c}\text { Right } \\
\text { hippocampal } \\
\text { sclerosis? }\end{array}$ & $\begin{array}{c}\text { No AED. } \\
\text { no recurrence }\end{array}$ \\
\hline 3 & 43:M & GTCS & None & $1 \mathrm{~min}$ & 2 & Concussion & None & $\begin{array}{c}\text { sharp wave } \\
\text { left midtemporal } \\
(R)\end{array}$ & $\begin{array}{c}\text { Left } \\
\text { Mesiobasal } \\
\text { Hamartoma? }\end{array}$ & $\begin{array}{l}\text { AED initiated. } \\
\text { No recurrence }\end{array}$ \\
\hline 4 & 20:M & GTCS & Visual aura & $15-30 \mathrm{~min}$ & 1 & None & None & Normal (R) & Normal & $\begin{array}{l}\text { AED initiated, } \\
\text { but discontinued due to side- } \\
\text { effects. No recurrence }\end{array}$ \\
\hline 5 & $32: M$ & GTCS & None & $15-30 \mathrm{~min}$ & 2 & None & $\begin{array}{l}\text { sleep deprivation } \\
\text { alcohol? }\end{array}$ & Normal (R) & Normal & $\begin{array}{c}\text { AED started. } \\
\text { No recurrence. }\end{array}$ \\
\hline 6 & $65: M$ & CPS & $\begin{array}{l}\text { Sensory } \\
\text { (Piloerection) }\end{array}$ & $15-30 \mathrm{~min}$ & 1 & None & None & $\begin{array}{l}\text { Normal } \\
(R / s \mid D)\end{array}$ & Normal & $\begin{array}{l}\text { Presented after } 3^{\text {rd }} \text { seizure. } \\
\text { Event while driving was the } \\
\text { first seizure. No recurrence } \\
\text { after initiation of AED. }\end{array}$ \\
\hline 7 & 20:M & GTCS & None & $30-45 \mathrm{~min}$ & 2 & None & $\begin{array}{l}\text { sleep deprivation } \\
\text { alcohol? }\end{array}$ & $\begin{array}{l}\text { Normal } \\
(\mathrm{R} / \mathrm{sID})\end{array}$ & Normal & $\begin{array}{c}\text { No AED. } \\
\text { no recurrence }\end{array}$ \\
\hline 8 & $39: F$ & GTCS & None & n.a. & 2 & None & sleep deprivation & $\begin{array}{c}\text { Sharp wave left } \\
\text { mid-temporal } \\
(\mathrm{R} / \mathrm{sID})\end{array}$ & Normal & $\begin{array}{c}\text { No AED. } \\
\text { no recurrence }\end{array}$ \\
\hline 9 & $61: F$ & GTCS & Visual aura & $1-5 \min$ & 1 & None & None & Normal & Normal CT & $\begin{array}{l}\text { AED initiated } \\
\text { no recurrence }\end{array}$ \\
\hline 10 & $67: M$ & GTCS & None & $15-30 \mathrm{~min}$ & 2 & $\begin{array}{c}\text { Wedge } \\
\text { Compression } \\
\text { T12-L1 }\end{array}$ & None & $\begin{array}{l}\text { Left temporal } \\
\text { slowing }(R)\end{array}$ & $\begin{array}{l}\text { Left anterior } \\
\text { temporal } \\
\text { arachnoidal } \\
\text { cyst }\end{array}$ & $\begin{array}{l}\text { AED initiated. } \\
\text { No recurrence. }\end{array}$ \\
\hline 11 & 21:M & GTCS & None & $1-5 \min$ & 3 & None & None & $\begin{array}{l}\text { Bifrontal spikes } \\
(R / s \mid D)\end{array}$ & Normal & $\begin{array}{l}\text { Presented after } 3^{\text {rd }} \text { seizure. } \\
\text { Event while driving was the } \\
\text { first seizure. No recurrence } \\
\text { after initiation of AED. }\end{array}$ \\
\hline 12 & 23:M & GTCS & $\begin{array}{l}\text { Vasovagal } \\
\text { symptoms }\end{array}$ & 4-5 min & 1 & None & None & Normal (R) & $\begin{array}{l}\text { T2/FLAIR } \\
\text { Punctuate foci } \\
\text { on MRI }\end{array}$ & $\begin{array}{l}\text { Presented after } 3^{\text {rd }} \text { seizure. } \\
\text { Event while driving was the } \\
\text { first seizure. No recurrence } \\
\text { after initiation of AED. }\end{array}$ \\
\hline 13 & $24: F$ & GTCS & Visual aura & $5 \mathrm{~min}$ & 2 & None & None & Normal (R) & Normal CT & $\begin{array}{c}\text { No AED. } \\
\text { Isolated seizure with } \\
\text { no recurrence. }\end{array}$ \\
\hline
\end{tabular}

1 = patient was able to actively control car and no accident resulted; $2=$ patient is not able to avoid subsequent car accident and does not recollect the event; 3 = passenger in the car pulled the car over due to abnormal behaviour of the driver and could avoid accident. GTCS = Generalized tonicclonic seizure, $\mathrm{CPS}=$ complex partial seizure, $\mathrm{SPS}=$ simple partial seizure, $\mathrm{AED}=$ antiepileptic drug

\section{Time driving before seizure}

Twelve out of 13 patients were driving for less than one hour. Of these twelve; five patients were driving for less than five minutes, four less than 30 minutes, one patient less than 45 minutes and in one patient this information was not available. One patient drove for approximately one hour.

\section{Ability to control the car and injuries}

Four FSWD patients were able to actively stop the car, all of these patients had a preceding "warning". Three had visual auras, one had vasovagal symptoms as described above. None of them experienced injuries.

Most of the patients $(n=7)$ were not able to stop the car, resulting in an accident. One patient suffered from a wedge compression fracture T12-L1, one experienced a concussion, and one patient crashed into a car in the opposite lane resulting in the death of the driver of the other car.

In two FSWD cases, the passengers were able to pull the car over, no injuries resulted.

\section{Provoking factors}

We could identify in four patients sleep deprivation as a contributing provoking factor for lowering the seizure threshold, two of these were also possibly associated with major alcohol consumption the night before. Nine patients had no evidence for provoking factors at all. None of our patients had evidence for chronic alcohol abuse or alcoholism.

\section{EEG and MRI results}

Nine out of 13 patients had normal routine EEG results, four of these had sleep deprived EEGs which were normal as well. Six of those with normal EEGs had normal MRIs, one showed cerebellar atrophy, one had a MRI finding suggestive of hippocampal sclerosis, and one had most likely entirely unrelated T2/FLAIR punctuate foci on MRI.

One patient had a left mid-temporal sharp wave; both on routine and sleep-deprived EEG. There were no corresponding findings on MRI.

Two patients had corresponding EEG and MRI findings (patient 3 and patient 10): one patient had a left mid-temporal 
sharp wave on routine EEG and a lesion on MRI strongly suggestive of a left mesio-basal hamartoma. The other patient presented with a left temporal slowing on routine EEG and showed an extensive left temporal arachnoid cyst.

One patient had bifrontal spikes (patient 11) both in routine and sleep deprived EEG suggestive of primary generalized epilepsy, MRI was normal in this patient. In keeping with this concept, this patient had two further GTCSs when presenting to the FSC and was considered to have newly diagnosed epilepsy.

\section{Outcome}

Outcome was overall excellent with no further seizure recurrence within one year; with antiepileptic treatment started in eight out of 13 patients (decision was based on risk analysis and/or patients request), and no treatment in five patients.

\section{DISCUSSION}

To our knowledge, our study is the first well documented series of patients with first seizures who were specifically investigated for the circumstances of associated driving. Over eight percent of the patients who presented to our First Seizure Clinic seizure had their first witnessed seizure while driving. It is very likely that this is a very conservative measure and that the prevalence is highly underestimated. People often do not obey driving guidelines for medical conditions, as driving is central to their daily activities and work obligations. ${ }^{20} \mathrm{We}$ had striking indications that several patients excluded in our study and lost to follow-up avoided contact with medical services to bypass any restrictions of their driving privileges. We identified several individuals with most likely FSWD, who simply walked out of the emergency room, particularly if there were no witnesses present. Patients referred from the emergency department to the Halifax FSC apparently did often not show up, particularly when the driving issue was raised by the ER physician.

The described trend of disobedience of driving guidelines and driving in spite of legal restrictions is widespread. It was found in $23.8 \%$ of patients with confirmed diagnosis of epilepsy ${ }^{21}$ and also described in intractable epilepsy, particularly if patents had not experienced a collision and were employed ${ }^{22}$.

Not surprisingly, in $23 \%(n=3)$ of our patients subsequent injuries occurred as the result of losing control of driving the car, in one case with fatal consequences for the other party. This percentage is alarming and supports the concept of most national and international guidelines observing seizure freedom for at least six months before approving driving privileges.

Yang suggests that either deficits in the level of consciousness, which includes mechanisms for maintaining an alert, attentive state, or the content of consciousness, which includes sensorimotor function, vision, and higher order integration, could adversely affect driving during seizures. ${ }^{23}$ Findings from their study suggest impairment in different aspects of consciousness in different types of seizures. It is not surprising, that generalized tonic-clonic seizures and to a much lesser extent complex partial seizures were the main seizure types in our patients as they will always impact consciousness and immediately affect the capability to drive a vehicle. However, we cannot rule out, that the index seizure was not the first seizure and that the patient had unobserved previous events which were either too subtle, occurred in sleep or had no witness in presence of an amnestic patient.
The fact that four patients had preceding simple partial seizures with visual phenomena is of great theoretical interest and will be discussed below in the conceptual part of this paper.

All four patients who were able to control and stop the car were alarmed by preceding simple partial seizures. However, our small data also shows, that the presence of a preceding short lasting simple partial seizure does not imply "automatically" preserved capability to steer a car, as two patients still lost control, in one case with fatal consequences (patient 2). In a study of patients with known epilepsy, using video games and a driving simulator to look at whether different types of seizures have different effects on driving ability, it was found that there are indeed differences between how different types of seizures affect driving ability. They found no evidence of impairment during subclinical seizures but evidence of marked impairment with secondarily generalized seizures. They also found evidence of driving impairment in some, but not all, partial seizures and absence seizures. ${ }^{23}$ This fact is of paramount importance for counselling, as patients frequently bring forward and assume that an "epileptic warning" will allow them enough time to pull over their car. The fear of the medico-legal implications of driving and seizure occurrence often requires the patient to balance the risk of another seizure while driving against losing significant autonomy in a mobile society.

The clinical outcome with regard to seizure freedom with and without AED was excellent in our patients raising the question, of the possibility of most of these seizures being situational related or provoked. Sleep deprivation and alcohol abuse as most frequently described provoking factors for both provoked seizures and new-onset epilepsy, could be only documented in less than a third of our patients (4 out of 13). In 4 out of 13 patients (patients 2, 3,8 and 10) either EEG or MRI or both were suggestive of symptomatic and most likely non-situational seizures. The number of these patients is too small to postulate an epilepsy-syndrome specific effect.

It is intriguing to further analyze possible underlying mechanisms leading to the co-occurrence of driving and seizure activation. There was no evidence for the first occurrence of reflex epilepsy with visual triggers and photosensitive epilepsy in our patients. ${ }^{24}$ We specifically explored the history of all patients for flickering light sources, sunlight reflections from snow or the sea or interruptions by roadside structures such as trees, fences etc. All patients underwent EEGs with photic stimulation over a wide range of frequencies with no evidence for photosensitivity even in patient 11 with most likely primary generalized epilepsy. ${ }^{25}$ It has been suggested for photosensitive patients who are also pattern-sensitive that generalized seizures and epileptiform discharges can occur if the normal excitation of visual cortex involves a certain "critical mass" of cortical area with subsequent hyperexcitation, synchronisation and seizure spread. ${ }^{26,27}$ It is interesting that 4 out of our 13 patients had preceding visual symptoms. Seizures induced by thinking or spatial tasks have been linked with dysfunction of the parietal lobe. ${ }^{28}$ It is well established that complex visuomotor tasks and pattern recognition play a major role in seizure activation in reading epilepsy. ${ }^{29}$

A recent study showed an increase of epileptiform activity in patients with focal epilepsy, during a task combining visual input and complicated situations over a significant duration, particularly when visual auras preceded the seizure. ${ }^{30}$ Cognitive 
performance tests ipsilateral to the seizure focus in temporal lobe epilepsy induced seizure occurrence in almost $10 \%$ of all patients. ${ }^{19}$ Standardized neuropsychological assessment in a large study group of focal epilepsy, consisting of reading, speaking, writing, written calculation, mental calculation, and spatial construction, induced activation of epileptiform activity on EEG in selected individuals. ${ }^{18}$ Kasteleijn-Nolst Trenité et al found impaired driving performance during subclinical focal and generalised epileptiform discharges in three out of six patients with epilepsy. ${ }^{31}$ Current knowledge and data basis make it still entirely speculative if complex neuropsychological tasks (including driving) may have impact on lowering seizure threshold in predisposed individuals who present with their first seizure occurrence.

Our data, focusing on patients with their first seizure while driving, emphasize the importance of a careful and "complete" history and investigations and a need for a standardized management algorithm in all these patients. ${ }^{11}$

From a conceptual point of view, first seizure patients and patients with either new-onset epilepsy or newly diagnosed epilepsy provide an excellent research opportunity to study clinical epileptogenesis from the very beginning. ${ }^{32} \mathrm{We}$ are currently wondering if integrating complex visual-motor tasks and pattern stimulation during EEG recordings in first seizure patients may allow new insights in the mechanism of FSWD. Our thinking is in line with two recent studies which analyzed driving performance by implementing video games during inpatient video/EEG monitoring or used prolonged video-EEG monitoring in the evaluation of fitness to drive. ${ }^{14,23}$

We are confident that our prospective cohort of patients with first seizures and newly diagnosed epilepsy will help to collect more valid sophisticated data and, ideally, contribute to the reduction of seizure related driving accidents and injuries.

\section{REFERENCES}

1. CCMTA.ca. CCMTA medical standards for drivers. [pdf on the Internet]. Ottawa: Canadian Council of Motor Transport Administrators. [2012 Aug 30]. Available from: http:// www.ccmta.ca/english/pdf/medical_standards_aug_2011.pdf.

2. cma.ca. Determining medical fitness to operate motor vehicles: CMA drivers guide (7th edition)[book on the Internet]. Ottawa: Can Med Assn; c 18223 [2006]. Available from: http:// www.cma.ca/index.php/ ci_id/18223/la_id/1.htm.

3. McGwin G. Relationship of CVD and car accidents. Can Fam Physician. 1998;44:2061-2.

4. Skurtveit S, Strom H, Skrivarhaug T, Morland J, Bramness JG, Engeland A. Road traffic accident risk in patients with diabetes mellitus receiving blood glucose-lowering drugs. Prospective follow-up. Diabetic Med. 2009;26:404-8.

5. Lonnen KF, Powell RJ, Taylor D, Shore AC, MacLeod KM. Road traffic accidents and diabetes: insulin use does not determine risk. Diabetic Med. 2008;25:578-84

6. Thaelwitzer F. Epileptiker als Autofahrer. Munch Med Wochenschrift. 1906;37:1818.

7. Warlow C. Driving after a first seizure. [editorial]. BMJ [serial on the internet]. 2010 Dec [cited 2011 July 12];341:c6890. Available from: http//www. bmj.com/content

8. Lund M. Epilepsy and the driving license. Hexagone Roche. 1974; 2:19-23.

9. Stollreiter E. Aktuelle fragen der sozialen und beruflichen eingliederungen von epileptikern. Arzneimittelforschung. 1963; $60: 142$
10. Fisher RS, Parsonage M, Beaussart M et al. Epilepsy and driving: an international perspective. Joint commission on drivers' licensing of the international bureau for epilepsy and the international league against epilepsy. Epilepsia. 1994;35:675-84.

11. Pohlmann-Eden BP, Beghi E, Camfield C, Camfield P. The first seizure and its management in adults and children. BMJ. 2006; 332(7537):339-42.

12. Bonnett LJ, Tudur-Smith C, Williamson PR, Marson AG. Risk of recurrence after a first seizure and implications for driving: further analysis of the multicentre study of early epilepsy and single seizures. BMJ (Clin Research Ed). 2010;341:c6477.

13. Holland P, Lane S, Whitehead M, Marson AG, Jacoby A. Labor market participation following onset of seizures and early epilepsy: findings from a UK cohort. Epilepsia. 2009;50(5): 1030-9.

14. Kamel JT, Christensen B, Odell MS, D'Souza WJ, Cook MJ. Evaluating the use of prolonged video-EEG monitoring to assess future seizure risk and fitness to drive. Epilepsy Behav. 2010; 19:608-11.

15. Krauss GL, Krumholz A, Carter RC, Li G, Kaplan P. Risk factors for seizure-related motor vehicle crashes in patients with epilepsy. Neurol. 1999;52(7):1324-9.

16. Millett CJ, Johnson AL, Thompson PJ, Fish DR. A study of the relationship between participation in common leisure activities and seizure occurrence. Acta Neurol Scand. 2001;103:300-3.

17. Aldenkamp AP, Arends J, Verspeek S, Berting M. The cognitive impact of epileptiform EEG-discharges; relationship with type of cognitive task. Child Neuropsychol. 2004;10(4):297-305.

18. Matsuoko H, Nakamura M, Ohno T, et al. The role of cognitive motor function in precipitation and inhibition of epileptic seizures. Epilepsia. 2005;46 (Suppl 1):17-20.

19. Helmstaedter C, Hufnagel A, Elger CE. Seizures during cognitive testing in patients with temporal lobe epilepsy: possibility of seizure induction by cognitive activation. Epilepsia. 1992;33: 892-7.

20. Finucane AK. Epilepsy, driving and the law. Am Fam Physician. 1999;59(1):199-200.

21. Tatum WO, Worley AV, Selencia ML. Disobedience and driving in patients with epilepsy. Epilepsy Behav. January 2012;23(1): 30-5.

22. Webster NJ, Crawford P, Thomas FM. Who's behind the wheel? Driving with medically intractable epilepsy. Am J Health Behav. 2011;35(4):485-95.

23. Yang L, Morland TB, Schmits K, et al. A prospective study of loss of consciousness in epilepsy using virtual reality driving simulation and other video games. Epilepsy Behav. 2010;18(3): 238-46.

24. Zifkin B, Andermann F. Epilepsy with reflex seizures. In: Wyllie E, editor. The Treatment of epilepsy:Principles \& practice. 5th ed. Philadelphia, Pa: Kluwer \& Lippincott; 2011. p. 305-31.

25. Seshia SS, Young GB, Zifkin BG. Guidelines for visual-sensitive EEG testing. Can J Neurol Sci. 2008;35(2):133-9.

26. Binnie CD, Findlay J, Wilkins AJ. Mechanisms of epileptogenesis in photosensitive epilepsy implied by the effects of moving patterns. Electrenceph Clin Neurophys. 1985;61:1-6.

27. Wilkins AJ, Binnie CD, Darby CE. Visually induced seizures. Prog Neurobiol. 1980;15:85-117.

28. Wilkins AJ, Zifkin B, Andermann F, et al. Seizures induced by thinking. Ann Neurol. 1982;11:608-12.

29. Wolf P, Mayer T, Reker M. Reading epilepsy: report of five new cases and further considerations on pathophysiology. Seizure. 1998;7:271-9.

30. Aldenkamp AP, Arends J. Effects of epileptiform EEG discharges on cognitive function: Is the concept of "transient cognitive impairment" still valid? Epilepsy Behav. 2004;5(1):25-34.

31. Kasteleijn-Nolst Trenité DG, Riemersma JB, Binnie CD, Smit AM, Meinardi $\mathrm{H}$. The influence of subclinical epileptiform EEG discharges on driving behaviour. Electroencephalogr Clin Neurophysiol. 1987;67(2):167-70.

32. Pohlmann-Eden B. Conceptual relevance of new-onset epilepsy. Epilepsia. 2011;52(suppl. 4):1S-6S. 